\title{
Role of interleukin-10 gene polymorphisms in the development of coronary artery disease in Chinese population
}

\author{
H.M. Xu and Y.R. Liu \\ Department of Gerontology, Huaihe Hospital of Henan University, Kaifeng, China \\ The authors contributed equally to this study. \\ Corresponding author: H.M. Xu \\ E-mail: xuhuimin21@163.com
}

Genet. Mol. Res. 14 (4): 15869-15875 (2015)

Received June 28, 2015

Accepted September 24, 2015

Published December 1, 2015

DOI http://dx.doi.org/10.4238/2015.December.1.38

ABSTRACT. The aim of this study was to investigate the association between three common SNPs $(-1082 \mathrm{~A} / \mathrm{G},-819 \mathrm{~T} / \mathrm{C}$, and $-592 \mathrm{~A} / \mathrm{C})$ in the interleukin $10(I L-10)$ gene, and the development of coronary artery disease. Between January 2013 and December 2014, 272 patients with coronary artery disease and control subjects (each) were recruited for this study from the Huaihe Hospital of Henan University. The IL-10-1082A/G, $-819 \mathrm{~T} / \mathrm{C}$ and $-592 \mathrm{~A} / \mathrm{C}$ gene polymorphisms were analyzed using a polymerase chain reaction-restriction fragment length polymorphism (PCR-RFLP) assay. Logistic regression analyses revealed an association between the AA and GA+AA genotypes of $I L-10-1082 \mathrm{G} / \mathrm{A}$ and an elevated risk of coronary artery disease, compared to the GG genotype [adjusted odds ratio $(\mathrm{OR})=2.31$ and $1.49 ; 95 \%$ confidence interval $(\mathrm{Cl})=1.29$ 4.19 and 1.04-2.12, respectively]. The AG+GG genotype was associated with a moderately increased risk of coronary artery disease in smokers (adjusted OR $=2.74 ; 95 \% \mathrm{Cl}=1.01-3.01$ ). In conclusion, the AA and GA+AA genotypes of $I L-10-1082 \mathrm{G} / \mathrm{A}$ were associated with an elevated risk of coronary artery disease; the $I L-10-1082 \mathrm{G} / \mathrm{A}$ gene polymorphism 
also interacted with the tobacco smoking habits, contributing to the development of coronary artery disease.

Key words: Interleukin-10; Coronary artery disease; Polymorphism

\section{INTRODUCTION}

Coronary artery disease remains the leading cause of mortality and morbidity worldwide; this disease is also the leading cause of death in China. The development of coronary artery disease is a complex process, including environmental and genetic factors. Many environmental factors have been reported to play an important role in the development of coronary artery disease, such as alcohol consumption, tobacco usage, higher body mass index (BMI), dyslipidemia, hypertension, and diabetes mellitus (Sun et al., 2014; Puaschitz et al., 2015; van Setten et al., 2015). Some studies have also reported that variations in genes, such as aldehyde dehydrogenase 2, GP78, CYP17A1, interleukin-6 (IL-6), and IL-17, as well MMP-1, contribute to the development of coronary artery disease (Zhang et al., 2011; Cha et al., 2014; Qintao et al., 2014; Xu et al., 2014; Dai et al., 2015; Wang et al., 2015).

A multitude of inflammatory markers have been reported to play an important in the development of atherogenesis (Maier et al., 2005; Rosenson, 2008). Interleukins are important factors that cause a chronic vascular inflammatory response to atherosclerosis (Aukrust et al., 2008; Tziakas et al., 2008). The encoding gene of IL-10 is located on chromosome 1 at the 1q31-1q32 junction. IL-10 is an anti-inflammatory T-cell cytokine. Experimental studies have reported that IL10 is a pro-inflammatory cytokine involved in both innate and acquired immune responses, which plays a critical role in the development of atherosclerosis (Cai et al., 2014; Chao et al., 2014; Yu et al., 2015). In this study, we investigated the possible association between three common SNPs (-1082A/G, -819T/C, and -592A/C) in the IL-10 gene and the development of coronary artery disease.

\section{MATERIAL AND METHODS}

\section{Study subjects}

Patients with proven coronary artery disease $(n=306)$ were recruited from the Huaihe Hospital of Henan University between January 2013 and December 2014. Coronary artery disease was diagnosed in patients when a diameter stenosis of $50 \%$ was observed in any of the main coronary arteries. Patients with a history of prior angioplasty, coronary artery bypass surgery, or myocardial infarction history were also included as coronary artery disease subjects. Subjects were excluded based on the following criteria: presence of congenital heart disease, peripheral arterial disease, any type of autoimmune disease, renal and liver disease, or cancers. Finally, 272 patients with coronary artery disease were enrolled to our study, at a participation rate of $88.89 \%$.

Two hundred and seventy two control subjects free of coronary artery disease were selected from among individuals who underwent a regular health examination at the hospital clinic between January 2013 and December 2014. The control subjects were age- and gender-matched with the patients. Cases and controls were interviewed using a standardized questionnaire, which included questions regarding their socio-demographic characteristics (age, sex, alcohol consumption, tobacco smoking, and body mass index). Detailed clinical data, including those on hypertension, diabetes mellitus, and total cholesterol (TC), triglyceride (TG), low density 
lipopolysaccharide cholesterol (LDL-c), and high density lipopolysaccharide cholesterol (HDL-c) levels, of patients with coronary artery disease was collected from their medical records. Blood samples $(5 \mathrm{~mL})$ and signed informed consent forms were obtained from each patient and control subject prior to their participation in the study. The study protocol was approved by the Clinical Research Ethics Committee of the Huaihe Hospital of Henan University.

\section{Genotyping}

The blood samples of patients with coronary artery disease and control subjects were collected in ethylene diamine tetra-acetic acid (EDTA)-coated tubes, and stored at $-20^{\circ} \mathrm{C}$ until use. The IL-10 -1082A/G, -819T/C, and -592A/C gene polymorphisms were analyzed using a polymerase chain reaction-restriction fragment length polymorphism (PCR-RFLP) assay. The forward and reverse primers used for this purpose were as follows: $/ L-10-1082 A / G$, 5'-TCATTCTATGTGCTGGAGATGG-3' and 5'-TGGGGGAAGTGGGTAAGAGT-3'; IL-10819T/C, 5'-GGTGAGCACTACCTGACTAGC-3' and 5'-CCTAGGTCACAGTGACGTGG-3'; and IL-10-592A/C, 5'-CCTGAGCACTAGGTGACTAGC-3' and 5'-GGTACCTCACAGTGACGTCC-3', respectively. The samples were amplified using the following cycling program: one cycle of DNA denaturation at $94^{\circ} \mathrm{C}$ for $5 \mathrm{~min} ; 30$ cycles of denaturation at $94^{\circ} \mathrm{C}$ for $1 \mathrm{~min}$, annealing at $55^{\circ} \mathrm{C}$ for $1 \mathrm{~min}$, and extension at $72^{\circ} \mathrm{C}$ for $2 \mathrm{~min}$; and a final extension at $72^{\circ} \mathrm{C} \mathrm{for} 5 \mathrm{~min}$. Quality control was ensured by blind genotyping of the subject samples. The PCR products were verified by a $2 \%$ agarose gel electrophoresis, staining with ethidium bromide, and ultraviolet light analysis in order.

\section{Statistical analysis}

Differences in the distributions of demographic and clinical characteristics between patients with coronary artery disease and control subjects were compared by the $\mathrm{x}^{2}$ - or $t$-test. The distribution of genotypes in the controls was tested for deviation from the Hardy-Weinberg equilibrium (HWE) using the goodness-of-fit $X^{2}$-test. The association between IL-10-1082A/G, $-819 \mathrm{~T} / \mathrm{C}$, and $-592 \mathrm{~A} / \mathrm{C}$ polymorphisms and development of coronary artery disease was determined by estimating the odds ratio $(\mathrm{OR})$ and $95 \%$ confidence interval $(95 \% \mathrm{Cl})$ by logistic regression. The major homozygous genotype of the IL-10-1082A/G, -819T/C, and -592A/C polymorphisms was used as a reference. The samples were statistically analyzed using the SPSS 21.0 package (SPSS Inc., Chicago, IL, USA). A P value $<0.05$ was considered to indicate a significant difference.

\section{RESULTS}

The demographic and clinical characteristics of patients with coronary artery disease and control subjects are summarized in Table 1. No significant difference was found between the patients and control subjects in terms of $\operatorname{sex}\left(X^{2}=0.00, P=1.00\right)$ and age $\left(X^{2}=0.36, P=0.55\right)$. Patients with coronary artery disease were more likely to have a higher $\mathrm{BMI}(t=6.99, \mathrm{P}<0.001)$, consume alcohol $\left(X^{2}=4.61, P=0.03\right)$, smoke tobacco $\left(X^{2}=58.26, P<0.001\right)$, and be diagnosed with hypertension $\left(X^{2}=16.66, P<0.001\right)$ and/or diabetes mellitus $\left(X^{2}=21.51, P<0.001\right)$, compared to the control subjects. In addition, patients with coronary artery disease showed higher levels of TC $(t=2.35, \mathrm{P}=0.01)$, LDL-c $(t=3.70, \mathrm{P}<0.001)$, HDL-c $(t=3.40, \mathrm{P}<0.001)$, and TG $(t=3.40$, $P<0.001)$, compared to the subjects in the control group. 
Table 1. Demographic and clinical characteristics of patients with coronary artery disease and control subjects.

\begin{tabular}{|c|c|c|c|c|}
\hline Variables & Patients (\%) & Controls (\%) & $x^{2}$-test or $t$-test & $P$ value \\
\hline \multicolumn{5}{|l|}{ Mean age, year } \\
\hline$<60$ & $152(55.88)$ & $145(53.31)$ & & \\
\hline$\geq 60$ & $120(44.12)$ & $127(46.69)$ & 0.36 & 0.55 \\
\hline \multicolumn{5}{|l|}{ Gender } \\
\hline Females & $202(74.26)$ & $202(74.26)$ & & \\
\hline Males & $70(25.74)$ & $70(25.74)$ & 0.00 & 1.00 \\
\hline Body mass index, $\mathrm{kg} / \mathrm{m}^{2}$ & $26.4 \pm 4.7$ & $23.7 \pm 4.3$ & 6.99 & $<0.001$ \\
\hline \multicolumn{5}{|l|}{ Alcohol drinking } \\
\hline Never & $115(42.28)$ & $140(51.47)$ & & \\
\hline Ever & $157(57.72)$ & $132(48.53)$ & 4.61 & 0.03 \\
\hline \multicolumn{5}{|l|}{ Tobacco smoking } \\
\hline Never & $94(34.56)$ & $183(67.28)$ & & \\
\hline Ever & $178(65.44)$ & 89 (32.72) & 58.26 & $<0.001$ \\
\hline \multicolumn{5}{|l|}{ Hypertension } \\
\hline No & $148(54.41)$ & $194(71.32)$ & & \\
\hline Yes & $124(45.59)$ & 78 (28.68) & 16.66 & $<0.001$ \\
\hline \multicolumn{5}{|l|}{ Diabetes mellitus } \\
\hline No & $197(72.43)$ & $240(88.24)$ & & \\
\hline Yes & $75(27.57)$ & $32(11.76)$ & 21.51 & $<0.001$ \\
\hline $\mathrm{TC}, \mathrm{mM}$ & $4.73 \pm 1.24$ & $4.50 \pm 1.03$ & 2.35 & 0.01 \\
\hline LDL-c, mM & $2.44 \pm 0.62$ & $2.26 \pm 0.51$ & 3.70 & $<0.001$ \\
\hline HDL-c, mM & $1.27 \pm 0.32$ & $1.19 \pm 0.22$ & 3.40 & $<0.001$ \\
\hline TG, mM & $2.43 \pm 1.06$ & $2.06 \pm 0.98$ & 4.23 & $<0.001$ \\
\hline
\end{tabular}

TC = total cholesterol; LDL-c = low density lipopolysaccharide cholesterol; HDL-c = high density lipopolysaccharide cholesterol; TG = triglyceride.

The genotype distributions of IL-10-1082A/G, -819T/C and -592A/C in the control group conformed to the Hardy-Weinberg equilibrium (HWE), and the $P$ values (for HWE) were $0.95,0.06$, and 0.63 , respectively (Table 2). We observed significant differences in the genotype distributions of IL10-1082A/G ( $\left.X^{2}=9.39, P=0.009\right)$; however, IL-10-819T/C and -592A/C exhibited no such differences. Logistic regression analysis helped associate the AA and GA+AA genotypes of $I L-10-1082 G / A$ with an elevated risk of coronary artery disease, compared to the GG genotype (adjusted OR $=2.31$ and $1.49 ; 95 \% \mathrm{Cl}=1.29-4.19$ and $1.04-2.12$, respectively). However, the $/ L-10-819 \mathrm{~T} / \mathrm{C}$ and $-592 \mathrm{~A} / \mathrm{C}$ gene polymorphisms were not significantly associated with increased risk of coronary artery disease.

Table 2. Association between the /L-10-1082A/G, -819T/C, and -592A/C gene polymorphisms and the development of coronary artery disease.

\begin{tabular}{lrrrrc}
\hline IL-10 gene & Patients & Controls & P for HWE & OR (95\%Cl) & P value \\
\hline -1082G/A & & & & & \\
GG & $105(38.60)$ & $132(48.53)$ & & $1.0($ Ref. $)$ & - \\
GA & $121(44.49)$ & $116(42.65)$ & & $1.31(0.90-1.91)$ & 0.14 \\
AA & $46(16.91)$ & $25(8.82)$ & 0.95 & $2.31(1.29-4.19)$ & 0.003 \\
GA + AA & $167(61.40)$ & $141(51.47)$ & & $1.49(1.04-2.12)$ & 0.02 \\
$-819 T / C$ & $110(40.44)$ & $118(43.38)$ & & $1.0($ Ref. $)$ & - \\
TT & $113(41.54)$ & $111(40.81)$ & & $1.09(0.74-1.61)$ & 0.64 \\
TC & $49(18.01)$ & $163(15.81)$ & 0.06 & $1.22(0.73-2.05)$ & 0.42 \\
CC & $162(59.56)$ & $154(56.62)$ & & $1.13(0.79-1.61)$ & 0.49 \\
TC + CC & $100(36.76)$ & $110(40.44)$ & & $1.0($ Ref. $)$ & - \\
$-592 A / C$ & $128(47.06)$ & $123(45.22)$ & & $1.14(0.78-1.68)$ & 0.47 \\
AA & $44(16.18)$ & $39(14.34)$ & 0.63 & $1.24(0.72-2.13)$ & 0.41 \\
AC & $172(63.24)$ & $162(59.56)$ & & $1.17(0.81-1.67)$ & 0.38 \\
CC & AC + CC & & & & \\
\hline
\end{tabular}

${ }^{1}$ Adjusted for sex, age, body mass index (BMI), alcohol drinking, tobacco smoking, hypertension, and diabetes mellitus. $\mathrm{HWE}=$ Hardy-Weinberg equilibrium; $\mathrm{OR}=$ odds ratio; $\mathrm{Cl}=$ confidence interval. 
The association between IL-10-1082G/A gene polymorphisms and the development of coronary artery disease was stratified based on alcohol consumption, tobacco smoking, and a diagnosis of hypertension and/or diabetes mellitus (Table 3). The AG+GG genotype was found to be associated with moderately increased risk of coronary artery disease in smokers (adjusted OR - 2.74; $95 \% \mathrm{Cl}=1.01-3.01)$.

\begin{tabular}{|c|c|c|c|c|c|c|}
\hline \multirow[t]{2}{*}{ Variables } & \multicolumn{2}{|c|}{ Patients } & \multicolumn{2}{|c|}{ Controls } & \multirow[t]{2}{*}{ OR $(95 \% \mathrm{Cl})$} & \multirow[t]{2}{*}{$P$ value } \\
\hline & $\mathrm{AA}$ & $A G+G G$ & AA & $A G+G G$ & & \\
\hline \multicolumn{7}{|c|}{ Alcohol drinking } \\
\hline Never & 47 & 68 & 69 & 71 & $1.41(0.83-2.39)$ & 0.18 \\
\hline Ever & 58 & 99 & 63 & 69 & $1.56(0.94-2.56)$ & 0.06 \\
\hline \multicolumn{7}{|c|}{ Tobacco smoking } \\
\hline Never & 41 & 53 & 88 & 95 & $1.20(0.70-2.04)$ & 0.48 \\
\hline Ever & 64 & 114 & 44 & 45 & $2.74(1.01-3.01)$ & 0.03 \\
\hline \multicolumn{7}{|c|}{ Hypertension } \\
\hline No & 58 & 90 & 94 & 100 & $1.46(0.92-2.31)$ & 0.09 \\
\hline Yes & 47 & 77 & 38 & 40 & $1.56(0.84-2.87)$ & 0.13 \\
\hline \multicolumn{7}{|c|}{ Diabetes mellitus } \\
\hline No & 78 & 119 & 115 & 125 & $1.40(0.94-2.09)$ & 0.08 \\
\hline Yes & 27 & 48 & 17 & 15 & $2.01(0.80-5.08)$ & 0.1 \\
\hline
\end{tabular}

\section{DISCUSSION}

Genetic polymorphisms in functional cytokines could change their expression, thereby influencing the development of vascular lesions (Weng et al., 2010; Khankhanian et al., 2013). IL10 is produced by T-lymphocytes, and is an important anti-inflammatory and immune-suppressive cytokine that regulates angiogenesis in many inflammation-related diseases (Bantis et al., 2008; Javor et al., 2014; Peng et al., 2015; Yu et al., 2015). The IL-10 gene is a candidate gene in the pathophysiological mechanism of auto-immune/inflammatory disease, as it can regulate both the cellular and humoral immunity. In this study, the AA and GA+AA genotypes of the IL-10-1082G/A polymorphism were found to be associated with an elevated risk of coronary artery disease; in addition, the IL-10-1082G/A polymorphism associated with tobacco smoking in the development of coronary artery disease.

Previous studies have reported an association between polymorphisms in the IL-10 gene and the development of cardiovascular disease (Karaca et al., 2011; Yu et al., 2012; Jin et al., 2013; Elsaid et al., 2014; Lin et al., 2014); however, the results of these studies have been inconsistent. Yu et al. (2012) discovered a significant association between the SNPs at positions -592C/A and $-819 \mathrm{C} / \mathrm{T}$ and susceptibility to ischemic heart disease in a Korean population. Jin et al. (2013), in a study comprising 249 patients and 132 unaffected controls selected from a Chinese population, reported an association between the $I L-10-592 \mathrm{~A} / \mathrm{C}$ polymorphism and increased risk of coronary heart disease. On the other hand, Elsaid et al. (2014), who conducted a case-control study with 108 Egyptian patients with coronary artery disease and 143 healthy subjects, reported that the G allele of IL-10-1082G/A was associated with an increased prevalence of coronary artery disease. Meanwhile, Lin et al. (2014), reported a correlation between polymorphisms in the IL-10 gene (IL-10$1082 \mathrm{G} / \mathrm{A}$ ) and the development of coronary artery aneurysm in a Taiwanese population (Lin et al., 
2014). However, other studies have reported inconsistent results. Karaca et al. (2011) discovered an association between the $I L-10-1082 \mathrm{~A} / \mathrm{G}$ polymorphism and the development of coronary heart disease, while $I L-10-819 T / C$ and $-592 A / C$ did not. A recent meta-analysis comprising 16 studies suggested that the $I L-10-1082 A / G$ polymorphism was associated with an increased risk of atherosclerosis (Chao et al., 2014). Wang et al. (2012), in a meta-analysis of 6 case-control studies conducted in a Caucasian population, suggested that the A allele of IL-10-1082A/G contributed to increased risk of coronary heart disease. In this study, the A allele of $I L-10-1082 \mathrm{G} / \mathrm{A}$ was correlated with increased risk of coronary artery disease. The discrepancies among the above results may be attributed to ethnic variations, differences in the source of patients and sample size, and to chance.

We also observed an association between the IL-10-1082A/G gene polymorphism and tobacco smoking habits in the development of coronary artery disease. Previous studies reported that tobacco smoking interacted with cytokine genes, contributing to the development of several diseases (Meisel et al., 2002; Kuo et al., 2014). Further studies are required to confirm our findings. Our study includes several limitations. Firstly, patients and controls were selected from a single hospital, which suggested that the selected controls may not be representative of the general population. Secondly, the sample size was relatively small; this limited sample size could result in a lack of power, which could explain our failure in finding an association with the IL-10 polymorphisms.

In conclusion, the results of our study suggested an association between the IL-101082A/G gene polymorphisms and an elevated risk of coronary artery disease; in addition, IL-10$1082 \mathrm{G} / \mathrm{A}$ interacts with the tobacco smoking habits in contributing to the development of coronary artery disease. Future studies using larger sample sizes, and employing either similar or different analytical strategies may help in elucidating the impact of these polymorphisms on the risk of coronary artery disease.

\section{Conflicts of interest}

The authors declare no conflict of interest.

\section{ACKNOWLEDGMENTS}

We acknowledge the helps from staffs in Huaihe Hospital of Henan University for correcting the blood samples.

\section{REFERENCES}

Aukrust P, Halvorsen B, Yndestad A, Ueland T, et al. (2008). Chemokines and cardiovascular risk. Arterioscler. Thromb. Vasc. Biol. 28: 1909-1919.

Bantis C, Heering PJ, Aker S, Schwandt C, et al. (2008). Influence of interleukin-10 gene G-1082A polymorphism on recurrent IgA nephropathy. J. Nephrol. 21: 941-946.

Cai Y, Kobayashi R, Hashizume-Takizawa T and Kurita-Ochiai T (2014). Porphyromonas gingivalis infection enhances Th17 responses for development of atherosclerosis. Arch. Oral Biol. 59: 1183-1191.

Cha E, Fu ZY, Ma YT, Zhu Q, et al. (2014). A novel polymorphism of the GP78 gene is associated with coronary artery disease in Han population in China. Lipids Health Dis. 13: 147.

Chao L, Lei H and Fei J (2014). A meta-analysis of interleukin-10-1082 promoter genetic polymorphism associated with atherosclerotic risk. Neurol. India 62: 130-136.

Dai CF, Xie X, Yang YN, Li XM, et al. (2015). Relationship between CYP17A1 genetic polymorphism and coronary artery disease in a Chinese Han population. Lipids Health Dis. 14: 16. 
Elsaid A, Abdel-Aziz AF, Elmougy R and Elwaseef AM (2014). Association of polymorphisms G(-174)C in IL-6 gene and $\mathrm{G}(-1082) \mathrm{A}$ in IL-10 gene with traditional cardiovascular risk factors in patients with coronary artery disease. Indian J. Biochem. Biophys. 51: 282-292.

Javor J, Králinský K, Sádová E, Červeňová O, et al. (2014). Association of interleukin-10 gene promoter polymorphisms with susceptibility to acute pyelonephritis in children. Folia Microbiol. 59: 307-313.

Jin H, Wang Y and Xu LX (2013). Association of interleukin 10 gene -592C/A polymorphism with coronary artery disease. Zhonghua Yi Xue Yi Chuan Xue Za Zhi 30: 724-728.

Karaca E, Kayıkçıoğlu M, Onay H, Gündüz C, et al. (2011). The effect of interleukin-10 gene promoter polymorphisms on earlyonset coronary artery disease. Anadolu. Kardiyol. Derg. 11: 285-289.

Khankhanian P, Baranzini SE, Johnson BA, Madireddy L, et al. (2013). Sequencing of the IL6 gene in a case-control study of cerebral palsy in children. BMC Med. Genet. 14: 126.

Kuo WH, Huang CY, Fu CK, Hsieh YH, et al. (2014). Effects of interleukin-10 polymorphisms and smoking on the risk of gastric cancer in Taiwan. In Vivo 28: 967-971.

Lin YJ, Lan YC, Lai CH, Lin TH, et al. (2014). Association of promoter genetic variants in interleukin-10 and Kawasaki disease with coronary artery aneurysms. J. Clin. Lab. Anal. 28: 461-464.

Maier W, Altwegg LA, Corti R, Gay S, et al. (2005). Inflammatory markers at the site of ruptured plaque in acute myocardial infarction: locally increased interleukin-6 and serum amyloid A but decreased C-reactive protein. Circulation 111: 13551361.

Meisel P, Siegemund A, Dombrowa S, Sawaf H, et al. (2002). Smoking and polymorphisms of the interleukin-1 gene cluster (IL-1alpha, IL-1beta, and IL-1RN) in patients with periodontal disease. J. Periodontol. 73: 27-32.

Peng X, Xu J, Wang P, Zhou J, et al. (2015). Interleukin-10-1082A/G polymorphism and diabetic nephropathy: a meta-analysis. Med. Sci. Monit. 21: 890-894.

Puaschitz NG, Strand E, Norekvål TM, Dierkes J, et al. (2015). Dietary intake of saturated fat is not associated with risk of coronary events or mortality in patients with established coronary artery disease. J. Nutr. 145: 299-305.

Rosenson RS (2008). Biomarkers, atherosclerosis and cardiovascular events. Expert Rev. Cardiovasc. Ther. 6: 619-622.

Sun Y, Yu X, Zhi Y, Geng S, et al. (2014). A cross-sectional analysis of the relationship between uric acid and coronary atherosclerosis in patients with suspected coronary artery disease in China. BMC Cardiovasc. Disord. 14: 101.

Tziakas DN, Chalikias GK, Tentes IK, Stakos D, et al. (2008). Interleukin-8 is increased in the membrane of circulating erythrocytes in patients with acute coronary syndrome. Eur. Heart J. 29: 2713-2722.

van Setten J, Išgum I, Pechlivanis S, Tragante V, et al. (2015). Serum lipid levels, body mass index, and their role in coronary artery calcification: a polygenic analysis. Circ. Cardiovasc. Genet. 8: 327-333.

Wang K, Dong PS, Zhang HF, Li ZJ, et al. (2015). Role of interleukin-6 gene polymorphisms in the risk of coronary artery disease. Genet. Mol. Res. 14: 3177-3183.

Wang Y, Zheng J, Liu P, Yu X, et al. (2012). Association between the interleukin 10-1082G\&gt;A polymorphism and coronary heart disease risk in a Caucasian population: a meta-analysis. Int. J. Immunogenet. 39: 144-150.

Weng KP, Hsieh KS, Hwang YT, Huang SH, et al. (2010). IL-10 polymorphisms are associated with coronary artery lesions in acute stage of Kawasaki disease. Circ. J. 74: 983-989.

Xu F, Sun Y, Shang R, Li M, et al. (2014). The Glu504Lys polymorphism of aldehyde dehydrogenase 2 contributes to development of coronary artery disease. Tohoku J. Exp. Med. 234: 143-150.

Yu GI, Cho HC, Cho YK, Park HS, et al. (2012). Association of promoter region single nucleotide polymorphisms at positions $-819 \mathrm{C} / \mathrm{T}$ and $-592 \mathrm{C} / \mathrm{A}$ of interleukin 10 gene with ischemic heart disease. Inflamm. Res. 61: 899-905.

Yu GI, Jun SE, Cho HC, Park KO, et al. (2015). Association of interleukin-10 promoter region polymorphisms with risk factors of Atherosclerosis. Int. J. Immunogenet. 42: 31-37.

Zhang X, Pei F, Zhang M, Yan C, et al. (2011). Interleukin-17A gene variants and risk of coronary artery disease: a large angiography-based study. Clin. Chim. Acta 412: 327-331. 